\title{
Discussion of Emotional Relation with Marriage Satisfaction in Couples of Ilam
}

\section{Farideh Mousavi}

Master of Degree Course in Clinical Psychology, Psychology Faculty, Science \& Research Branch Islamic Azad University, Ilam, Iran; Email: f.mosavi92@gmail.com

\author{
Shahram Mami \\ Doctorate of Psychology, Psychology Faculty, Science \& Research Branch, Islamic Azad University, Ilam, Iran \\ Corresponding Author. Email: Shahram.mami@yahoo.com
}

\section{Doi:10.5901/mjss.2015.v6n6s6p37}

\begin{abstract}
The Aim of this research is to discuss emotional relation with marriage satisfaction of couples in llam. The statistical society consisted of couples of llam. The method was correlative one. Also, the data collected in questionnaire are measurement. Based on report of registration marriage bureau of llam, the couples were 2000 people at 2013-2014. In order to collect data and as for background of subject, librarian method has been used and for collecting data, closed answer question has been used which consist of: 1- emotional relations 2- Enrich marriage satisfaction questionnaire. The findings showed that there is significant relation between emotional relation and marriage satisfaction of llam. Also, there is significant relation between satisfaction with gender and emotional relation in llam couples.
\end{abstract}

Keywords: Emotional Relation, Marriage Satisfaction, Ilam

\section{Introduction}

Family is producer of mean and concept and needs continued relation as most fundamental institute. Each family produces fundamental and abiding hypothesizes in world in which live and regardless difference or conflict between members of family, the satisfaction is required to acceptance or belief to sum of abiding or shared structures about family and its relation with social environment and marriage satisfaction is converted to important variable. By commencing shared life and make marriage relation, marriage satisfaction is a thought variable and is regarded as personal property of husband and wife. Interaction and marriage relation is a suitable key and in other word, when family use effective communicational pattern, it has clear transmission and comprehension from it and mental needs of family are satisfied and continues its participation. (1) Quality of marriage relation covers marriage compatibility and marriage happiness, high quality shows subjective specifications between spouses, like following, good relation and lacking confliction which are specifications. Also, scale of satisfaction is covered. One of the emotional needs of couples is relation as well as sincerely which regards as important source for happiness and marriage satisfaction (2). Marriage satisfaction is process that make during life and its necessary is tastes, recognize personality specifications, make behavioral patterns. (3). Marriage satisfaction is general evaluation from marriage relation or lovely affairs. Marriage satisfaction can be reflection from happiness or combination of be happiness because of special factors. Scale of marriage satisfaction is considered as psychological situation which doesn't make itself but needs efforts. Especially in early years, marriage satisfaction is instable more and relation between couples is endangered more. (3) there are different factors in marriage satisfaction: like, mental health, sexual affairs, educate life skills, type of society, marriage age, graduation, belief problems and sincerity relations. One of the factors of marriage satisfaction is enabling for solving conflicts between couples. Silimin 2001 believed that it is so pleasant for the couples to overcome on their problems. In this case, solving conflict is suitable for marriage. Result of solving conflict can make new recognition and more suitable for marriage. The skills of solving problem are accurate relation, decision, govern conflict of family, financial management and participate in social activity. From factors which influence upon marriage dissatisfaction is addiction. A research has been performed by Christopher at 2000 about violation between addicted couples showed that addicted men have more violations to their spouses. This research, showed lesser scale of inclination for making emotional relation with spouse. The another study by Scofer and Stuart at 20005 as discussion violation and cognitive performance between addiction and their spouses showed that misuse of drug is related with aggressive and misuse of drug is regarded as more dangerous strategy. In addition to it, 
Neuro cyckologic manners are related with misuse of drug. This study has been performed on 31 couples who were male, addicted and leaving drug. Another factor is violation, violation and its actions are difficulties in any society. Family violation points to manner of aggressive and are influenced on men and women in any level. Family violation points to manner of aggressive which happens in relation of couples and described as spouse disturbance, marriage violation, wife disturbance, partner disturbance. (4) one of the best definitions of family or spouse disturbance is offered by Barnet 2003 and he described it as pattern from invasions and compulsory behaviors like physical, sexual, mental violations and economical pressures and threats which are applied by persons. In health marriage relation, marriage and respect are important problems, the spouses shall customize their behaviors in framework of respect in any case whether happiness or unhappiness, satisfaction and dissatisfaction. Since respect and emotion is more suitable than mental and bodily structure of woman and morale feeling is made in family, the woman shall consider that her respect to her husband is mental need. (5). Verbal and non verbal relation are required in any ceremonies. The researchers showed that between 50 to $93 \%$ of daily times spent for social relations. About verbal relations, the studies showed that verbal ability of women of her skill in applying language as pointed before is more than men. There is difference between two genders because of smile, situation of body, move hands and gesture and mode of face. The authorities believed that important of non verbal behaviors is so important from social aspect. Men have more calmness from mode and bodily situation and face and women are unrest. Women smile more than men during speaking and showed more skill in receiving non verbal messages. (6). Landis 2003 concluded the results in his research as discussion marriage compromise of students: six problems are: sexual or economical problems, recreation and social relation, man and woman family relations, sexual problems and select friends, sexual problems are so important, in this case the couples are consent and many of husbands compliant it. Chan 2005 considered relation between emotional intelligence and marriage satisfaction and showed that emotional intelligence especially indicators like sympathy, emotion control and self awareness has relation with marriage satisfaction. Bochgar 2003 considered relation of prestige styles with marriage satisfaction and concluded that more correlation is about marriage satisfaction. As for above, the researcher is discussing emotional relation with marriage satisfaction in couples of llam.

\section{Method}

Methodology is correlative. Also, data collected from questionnaire are measurement. The statistical society consists of couples of llam. Based on report of registration marriage bureau, the couples were 2000 people at 2013-2014. In order to collect data, librarian method has been used and in order to collect documented data, closed answer questionnaire has been used which are emotional relation and Enrich marriage satisfaction questionnaire.

\section{Findings}

In any research, one of the sections of process is to discuss population variables which is so important, thus the analysis will be important. In table «1», population data are shown in terms of age, occupation, gender, graduation, duration of marriage and family dimensions.

Table 1. General table pertain to descriptive statistics of respondents

\begin{tabular}{|l|c|c|c|c|c|c|}
\hline Value & \multicolumn{2}{|c|}{ Low } & \multicolumn{2}{c|}{ Medium } & \multicolumn{2}{c|}{ High } \\
\hline Variable & abundance & Percent & Abundance & Percent & Abundance & Percent \\
\hline Age & 9 & $2 / 8$ & 71 & $22 / 2$ & 154 & $28 / 1$ \\
\hline Occupation & 12 & $3 / 8$ & 50 & $15 / 6$ & 160 & $50 / 2$ \\
\hline Gender & 50 & $17 / 6$ & 131 & $40 / 4$ & 190 & $59 / 3$ \\
\hline Graduation & 27 & $8 / 4$ & 95 & $29 / 7$ & 171 & $53 / 4$ \\
\hline Duration of Marriage & 54 & $16 / 9$ & 101 & $31 / 6$ & 118 & $36 / 9$ \\
\hline Family Dimension & 6 & $1 / 9$ & 144 & $45 / 2$ & 170 & $53 / 1$ \\
\hline
\end{tabular}

The results obtained from research showed that $59 / 1 \%$ were male and $409 \%$ female and also $84 \%$ had under diploma and diploma and $29 / 7 \%$ had associate degree, $53 / 4 \%$ bachelor and $8 / 4 \%$ had master degree. More abundance for respondents ages $31-40$ years with average $48 / 1 \%$ and the lowest abundance as under 50 to up with $2 / 8 \%$ and $3 / 8$ of respondents were unemployment, 50\% employee, 15/6\% self employed and 30/6\% housewife. Based on statistics, $36 / 9 \%$ married since 5 years, 31/6\% between 5 to 10 years, $16 / 9 \%$ between 10 to 15 years and $14 / 7 \%$ married more than 15 years. 


\subsection{Results of Analysis Data}

\subsubsection{Is there significant relation between marriage satisfaction and emotional relation?}

Table 2. Correlation coefficient test of Pearson for first hypothesis

\begin{tabular}{|c|c|c|c|}
\hline Hypothesis & Pearson correlation coefficient & Significant level of two domains & Result \\
\hline 1 & $0 / 689$ & 0.000 & $\mathrm{H}_{0}$, rejected \\
\hline
\end{tabular}

For above hypothesis, the crisis value is 0/0000 or significant level which is obtained by SPSS. As for table 2-4, credit value for first hypothesis is equal to 0/0000 and lower than $0 / 05$, as result, $\mathrm{HO}$ is rejected and it can be said there is relation between marriage satisfaction and emotional relation. Since Pearson coefficient value is 689 , it can be said that the relation is positive and severity of relation is so much. (Between 0/6 to 1 is sever)

\subsubsection{Is there significant difference between men and women about marriage satisfaction?}

Table 3. T test with two independent samples

\begin{tabular}{|c|c|c|c|c|c|c|c|c|c|}
\hline \multirow{3}{*}{ Marriage satisfaction } & \multicolumn{2}{|c|}{ Variance equality Test } & \multicolumn{7}{|c|}{ Average equality Test } \\
\hline & $\mathbf{F}$ & Sig. & $\begin{array}{c}\text { statistics } \\
\mathbf{t}\end{array}$ & df & decision for equality criteria & Average difference & Diferenence Error & Low Limit & \\
\hline & 1.253 & 0.264 & -3.771 & 318 & 0.000 & -0.93255 & 0.24731 & -1.41912 & -0.44598 \\
\hline
\end{tabular}

Crisis value for above hypothesis was 0/246 or same significant level which has been tested by SPSS. As for table3-4, the statistics consists of two tests, first test for variance equality with value 1/253 for statistics $\mathrm{F}$ and with decision 0/246 which certify variance equality. That means as for data, marriage satisfaction is equal between men and women. Second test is compare averages which equals to $0 / 000$ as sig)tailed ((2- and smaller than $5 \%$ and there is sufficient reason for reject it. By inequality of variances, this result will be obtained. Thus, it can be said there is significant difference between marriage satisfaction in men and women.

1- Since variable of marriage satisfaction is higher than a, then equality of variances is certified. Thus, we see marriage satisfaction variable in first column, otherwise, discuss second column.

Sig (2-tailed $)=p$-value $=0 / 246>0 / 05=a$

2- Digits show high and low limit without zero and confirms hypothesis $\mathrm{HO}$.

3- Difference if significant, then, there is significant difference between marriage satisfaction between men and women.

\subsubsection{Is there significant relation between men and women?}

$\mathrm{HO}$ : there is not significant difference between men and women about emotional relation.

$\mathrm{H} 1$ : there is significant difference between men and women about emotional relation.

Table 4. T test with two independent samples

\begin{tabular}{|c|c|c|c|c|c|c|c|c|c|}
\hline \multirow{3}{*}{ Emotional relation } & \multicolumn{6}{|c|}{ Variance equality test } & \multicolumn{6}{|c|}{ Average equality test } \\
\cline { 2 - 10 } & $\mathbf{F}$ & $\mathbf{S i g}$. & $\begin{array}{c}\text { Statistics } \\
\mathbf{t}\end{array}$ & $\mathbf{d f}$ & Scale for equality decision & Average difference & Standard error & Low Limit & High Limit \\
\cline { 2 - 9 } & 2.707 & 0.101 & -3.210 & 318 & 0.001 & -1.05776 & 0.32954 & -1.70611 & -0.40940 \\
\hline
\end{tabular}

For above hypothesis, crisis value is 0/101 of significant level which is obtained by SPSS. As for table 4, the statistics is 2/707 for $\mathrm{F}$ with decision 0.101 showed that the hypothesis is rejected. It means as for data of samples, the variance is equal. Second text equals to variances (sig(2-taild).) and equals to 0/001 which is smaller than $5 \%$ and there are sufficient reasons for reject it. As for inequality of variances, this same result will be obtained. Thus, there is significant difference between men and women.

1- Since variable of emotional relation is pertain to variance and greater than $a$, then equality of variances is confirmed, thus we see emotional variable in column one, otherwise, discuss second column: 
Sign (2-tailed)p-value=0/101 0/05=a

2- digits in column show low and high limit and not zero which its rejection for $\mathrm{HO}$.

3- Difference is significant, then average of emotional relation is significant between men and women.

\section{Conclusion}

About first hypothesis about significant relation between marriage satisfaction, findings of Houston and et al, 2001 in study which lapsed 13 years, by studying on 168 couples, they considered first roots of marriage dissatisfaction of couples and divorce. These researchers cite that early marriage, there is happiness and positivism which convert to pale lovely affairs and lacking consent and grief and unhappiness. The couples, who can maintain their lovely affairs somewhat, remain as married otherwise, separate. Thus, the couples shall use methods based on interest and respect (Bahari, 2006). Discussion relation between marriage satisfaction and their flexibility showed that more similarity between couples, satisfaction is so much. Thus, it can be concluded that parallelism in flexibility from personality specification of couples who have high marriage satisfaction. (Mosahebi, 2004) vail concluded that sum of negative patterns make relation and problematic behaviors are derived from these patterns. These patterns are: interactive separation, without attention, interactive reproof and much expectancy (translate by pourabedi, Naini and Monshi, 2001). Also, Amini qomin 2001 in his research named discussion relation of feeling expression and marriage satisfaction concluded that feeling expression influences on marriage satisfaction and two variables have significant and positive relation. 2- About second hypothesis which show difference about marriage satisfaction between men and women, Berzinak 2004 and Trudel 2002 concluded that women have low marriage satisfaction to men, the findings are different about marriage satisfaction and its difference. In previous research Huston, Kaflin, 2002 reported differences between men and women about marriage satisfaction. In these researches, men compared women were facilitators in sexual relations and concentrated on pleasure. In any case, non conformity findings about marriage satisfaction between men and women show the satisfaction depends on two persons who have marriage relation and satisfaction or dissatisfaction is derived from marriage texture till his gender and depends on conformity of couples. In research by Sherry adams 20004 which has performed in relation to marriage satisfaction between women of England, the parties simultaneous satisfaction is so important. Talo Nans 2007 performed research on Brazilian women a s marital problems and couple satisfaction and the results showed that the most important living problems are economical, children, sexual interest, jealous of wife or husband. There are differences in responding like women sexual relations and feeling expression as one of their problems with their spouses. This research showed that some of problems influence positive and negative effects on couples satisfaction.

\section{References}

Godazri M. Navabinejad Sh. Mohsenzadeh, 2009, Discussion Effectiveness of Group Consulting with Relation Approach on increment of Couples Efficiency, women researches, 1, 58-75

Pielage, S.B., Barelds, D. P. H., J. Gerlsma., C. P. D. R., Schaap. (2006). Adult attachment and couples verbal and nonverbal communication patterns in a stressful situation

Ahmadi, Khodabakhsh, Marzabadi Esfandiyar et al, 2005, Discussion marriage status and marriage compatibility between staff of Iranian Guard Corps, 141-152

Heidari Tafreshi, Gholamhossein, 2012, Modeling Strategy in determination of interest style and control source with marriage satisfaction in members of scientific board of Islamic Azad University, Roudehen Branch, Education Management Research Magazine, yaer 3th, continuation 11, pp 23-44

Huber, C. H., Navarro, R. L., Womble, M. W., \& Mumme, F. L. (2010). Family Resilience and Midlife Marital Satisfaction. The Family Journal: Counseling and Therapy for Couples and Families, 1-10.

Adams, R.B., Laursen. (2001). The organization and dynamics of adolescent conflict with parents and friends, journal of marriage and the family, vol. 63. Pp, 97-110. 